Academic Platform Journal of Engineering and Science

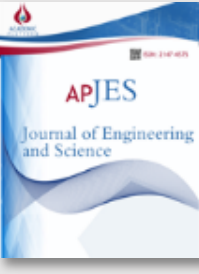

\title{
Investigation of Structural and Morphological Properties of Zno Nanoflowers on Biocompatible Polymeric Substrate
}

\author{
${ }^{*}$ Sinan Temel, ${ }^{2}$ Fatma Özge Gökmen, ${ }^{3}$ Elif Yaman \\ ${ }^{1}$ Bilecik Seyh Edebali University, Central Research Laboratory ,11230, Bilecik, Turkey, sinan.temel@bilecik.edu.tr, \\ ${ }^{2}$ Bilecik Seyh Edebali University, Central Research Laboratory ,11230, Bilecik, Turkey, fatmaozge.gokmen@bilecik.edu.tr, \\ ${ }^{3}$ Bilecik Seyh Edebali University, Central Research Laboratory ,11230, Bilecik, Turkey, elif.yaman@ bilecik.edu.tr, \\ Research Paper \\ Arrival Date: 19.02.2019 \\ Accepted Date: 17.07.2019
}

\begin{abstract}
In this study, acrylic acid (AA) biocompatible hydrogels were prepared and used as a polymeric substrate for zinc oxide (ZnO) nanoflower. Acrylic acid hydrogels were synthesized by free radical polymerization technique. ZnO nanoflowers on hydrogels ( $\mathrm{ZnO} / \mathrm{PAA})$ were prepared for the first time in literature by Chemical Bath Deposition technique at a very short deposition time (30 minutes). Structural and morphological properties of $\mathrm{ZnO}$ nanoflowers on PAA hydrogels were examined by X-ray diffraction (XRD), Fourier Transform Infrared Spectroscopy (FT-IR) and Field Emission Scanning Electron Microscopy Energy Dispersive of X-Ray (FESEM-EDX) respectively. Distribution of ZnO nanoflower on PAA hydrogels was determined by using elemental mapping. The XRD patterns showed that ZnO nanoflowers were fully formed on hydrogels. The FT-IR spectrum proved the characteristic absorption peaks of ZnO. FESEM images showed that the homogeneous morphology of ZnO nanoflowers. Nanoflowers were synthesized with an average size of $700 \mathrm{~nm}$. XRD, FT-IR spectroscopy and FESEM-EDX analysis evidenced the successful synthesize of novel $\mathrm{ZnO} / \mathrm{PAA}$ biocompatible nanocomposite hydrogels.
\end{abstract}

Keywords: Poly Acrylic acid, Hydrogel, Chemical Bath Deposition, $\mathrm{ZnO}$ nanoflower.

\section{INTRODUCTION}

Nanotechnology is the refer of working at the scale of individual molecules through science and technology around the world. According to the surge of a relevant number of publications, a great deal of interest on $\mathrm{ZnO}$ nanostructures is increasing recently. $\mathrm{ZnO}$ is mostly used in optoelectronic applications due to its wide band gap (Eg-3.3eV at $300 \mathrm{~K})$ and large exciton binding energy $(60 \mathrm{meV})$. Among different metal oxide nanoparticles, $\mathrm{ZnO}$ nanoparticles have great importance owing to their wide application areas such as chemical sensor, storage devices, bio-sensor, gas sensors, optoelectronic devices and window materials for solar cells. Various synthesis methods have been developed to grow a variety of $\mathrm{ZnO}$ nanostructures, including, nanoparticles, nanoflowers, nanowires, nanotubes, nanorods, nanobelts, etc [1-6].

A three dimensional (3D) networks of polymers made of both natural and synthetic materials dominating high number of flexibility is called hydrogels. In physical conditions, they are able to contain high amount of water and they can be characterized easily, it makes them an ideal material for variable applications. Hydrogels have characteristics properties like a desired functionality, reusability, reversibility, sterilizability and biocompatibility [7-10]. Due to these properties, hydrogels were selected as a substrate for nanoflower like $\mathrm{ZnO}$ particles.
There are only a few reports about deposition of $\mathrm{ZnO}$ nanoparticles on biocompatible hydrogels [11-13]. Due to its high specific surface area, excellent hydrophobicity and oxidizing ability, $\mathrm{ZnO}$ has been widely used to inhibit the growth of microorganisms. Reducing $\mathrm{ZnO}$ particles to nanoscale provides them ability to kill bacteria rapidly [14]. In this case, the use of $\mathrm{ZnO}$ nanoparticles together in biocompatible polymeric substrate should be improved to enhanced antibacterial property.

In these reports, $\mathrm{ZnO}$ nanoparticles deposition lasts about 24 hours. In the present work, ZnO/PAA biocompatible nanocomposite hydrogels were deposited via Chemical Bath Deposition (CBD) Technique. CBD is a cost effective and simply applicable technique. $\mathrm{ZnO}$ nanoparticle deposition by CBD can be carried out in a very short time compared to other methods. ZnO/PAA biocompatible nanocomposite hydrogels were successfully deposited at a very short deposition time like 30 minutes. Shorter deposition time provides energy efficiency and time saving.

\section{EXPERIMENTAL SECTION}

Synthesize of two types of hydrogels (PAA and ZnO/PAA) and characterization of obtained materials were described in this section. 


\subsection{Materials}

Acrylic Acid (AA) (Sigma), N,N'methylenebisacrylamide (N,N'-MBAAm) (Sigma) and ammonium per sulphate (APS) (Sigma) were used for synthesized hydrogels. Zinc nitrate hexahydrate $\mathrm{Zn}\left(\mathrm{NO}_{3}\right)_{2} \cdot 6 \mathrm{H}_{2} \mathrm{O}$ (Sigma), ammonia solution $(\% 28 \mathrm{v} / \mathrm{v})($ Merck) and distilled water were used for preparation of $\mathrm{ZnO}$ nanoflower on PAA hydrogels.

\subsection{Synthesize of PAA hydrogels}

The poly acrylic acid hydrogel solution containing monomer (acrylic acid), initiator (APS), crosslinking agent (N,N'MBAAm) and solvent (distilled water) were poured into PVC straws and heated in a temperature-controlled water bath $\left(\right.$ at $80^{\circ} \mathrm{C}$ ) for $2 \mathrm{~h}$. Then, the PVC straws were removed from bath and cut into cylindrical discs (3-4 mm in length) with a knife in same shape, and the hydrogels were dried in air before kept in vacuum oven $\left(35^{\circ} \mathrm{C}\right)$ [15].

\subsection{Synthesize of flower-like ZnO on PAA substrates}

$0.1 \mathrm{M}$ Zinc nitrate hexahydrate $\mathrm{Zn}\left(\mathrm{NO}_{3}\right)_{2} \cdot 6 \mathrm{H}_{2} \mathrm{O}$ solution was prepared in distilled water of $100 \mathrm{ml}$. Then, it was stirred with a magnetic stirrer. The $\mathrm{pH}$ of the solution was fixed to 10 while the solution was stirred, with adding ammonia solution $(\% 28 \mathrm{v} / \mathrm{v})$ drop by drop. After the bath was prepared, swollen cylindrical disc hydrogels substrates were thrown into the solution. The bath solution was stirred by temperature-controlled magnetic stirrer at $85^{\circ} \mathrm{C}$ in optimized minimum deposition time. The obtained samples were washed with distilled water and dried at room temperature [16-17]. Schematic diagram of general experimental procedure was seen in Fig.1.



Figure 1. Schematic diagram of $\mathrm{ZnO}$ nanoflowers on PAA hydrogels production.

\subsection{Characterization of ZnO Nanoflowers on Poly Acrylic Acid Hydrogels}

The synthesized $\mathrm{ZnO}$ nanoflower on PAA hydrogels were primarily investigated by X-ray diffraction (XRD), Fourier Transform Infrared Spectroscopy (FT-IR) and Field Emission Scanning Electron Microscopy (FESEM) for structural and morphological analysis. The crystal structure of the PAA hydrogel and $\mathrm{ZnO}$ nanoflower on PAA hydrogel were investigated by Panalytical Empyrean X-ray diffractometer using $\mathrm{CuK}_{\alpha}(\lambda=1.5405 \dot{\mathrm{A}})$ radiation in the $2 \theta$ range $20^{\circ}-60^{\circ}$. The presence and absence of the $\mathrm{ZnO}$ nanoflower vibrational modes were examined by FT-IR (Perkin Elmer, Spectra 100). The wave number range is 400$4000 \mathrm{~cm}^{-1}$. ATR mode was used and each spectrum was scanned 4 times and worked at a resolution of $4 \mathrm{~cm}^{-1}$. FESEM was used to confirm the size and shape of the $\mathrm{ZnO}$ nanoflowers on hydrogels. FESEM samples were prepared by coated with $2 \mathrm{~nm}$ of gold/palladium using a Qourum Sputter coater, and imaged using a Zeiss Supra $40 \mathrm{VP}$ FESEM at a working distance of $9 \mathrm{~mm}$ and at $15 \mathrm{kV}$. Elemental amounts and distributions of $\mathrm{ZnO}$ nanoflowers were shown by EDX and mapping images respectively.

\section{RESULTS AND DISCUSSION}

The X-ray measurements of the PAA hydrogel and $\mathrm{ZnO}$ nanoflower on PAA hydrogel were taken at the room temperature at $45 \mathrm{kV}$ and $40 \mathrm{~mA}$. In Fig. 2, XRD patterns of PAA hydrogel and $\mathrm{ZnO}$ nanoflower on PAA hydrogel have been given comparatively. According to XRD results, PAA hydrogel has amorphous structure. $\mathrm{ZnO}$ nanoflower on PAA hydrogel has polycrystalline nature. $\mathrm{ZnO}$ nanoflowers has matched completely with the hexagonal structured $\mathrm{ZnO}$ (ICDD: 98-003-1052). The XRD patterns showed that ZnO nanoflowers were fully formed on PAA hydrogels.

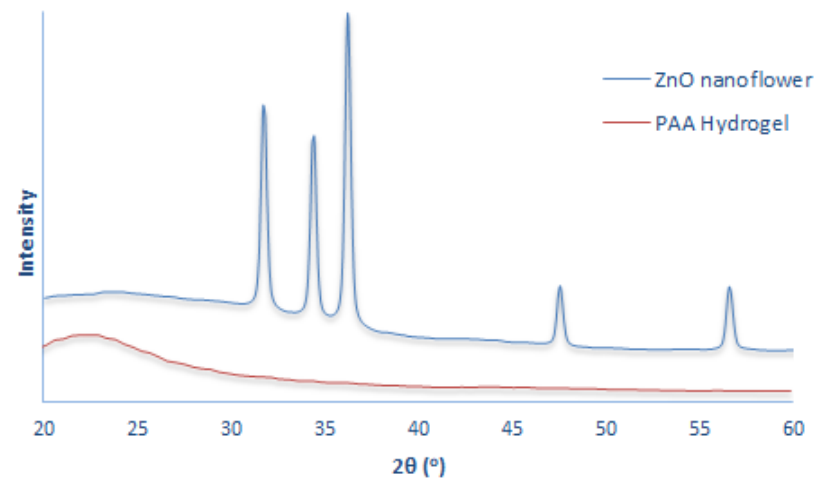

Figure 2. XRD patterns of PAA hydrogel and $\mathrm{ZnO}$ nanoflowers on PAA hydrogel.

FT-IR spectroscopy is performed in order to quickly establish the presence or absence of the various vibrational modes present in synthesized structures. FT-IR functional groups of PAA and $\mathrm{ZnO} / \mathrm{PAA}$ hydrogels were given in Fig. 3 and Table 1 .

The spectrum of interference pattern obtained in FT-IR images clearly shows that the characteristic absorption peaks of Zn-O $2000 \mathrm{~cm}^{-1}, 2152 \mathrm{~cm}^{-1}$ and $3835 \mathrm{~cm}^{-1}$ [18]. Swelling and water retention properties of PAA hydrogels exhibits by electrostatic interactions and $\mathrm{H}$-bonding between the $\mathrm{COO}^{-}$ groups. FT-IR results demonstrated of chemical interactions between $\mathrm{ZnO}$ and polymer. 

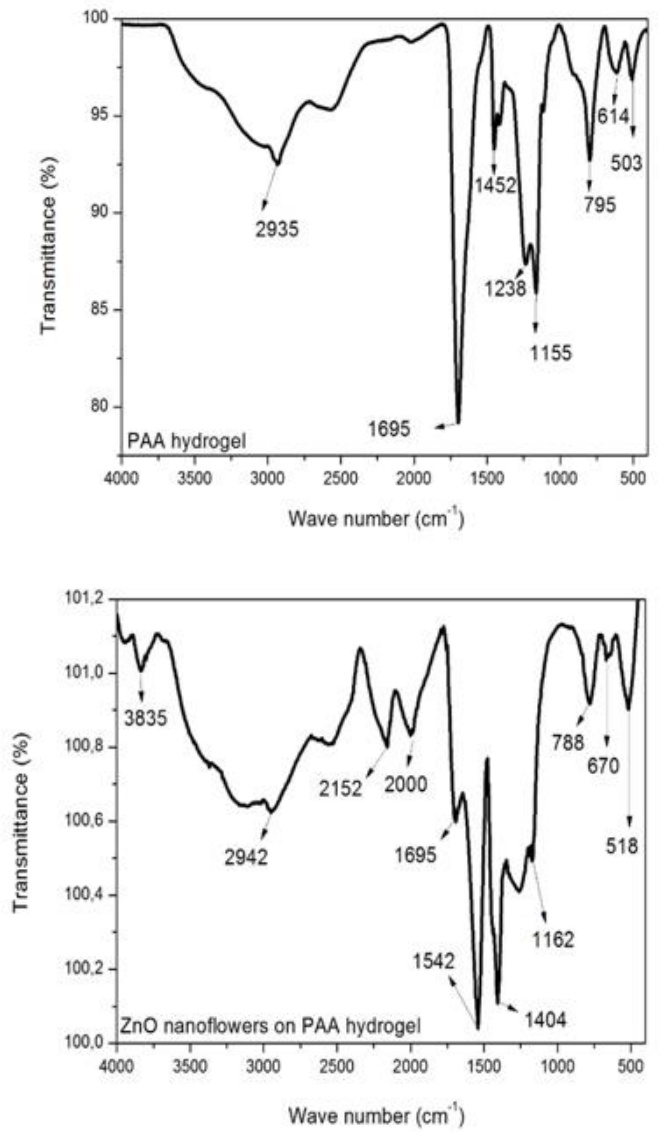

Figure 3. FT-IR spectra of PAA hydrogel and $\mathrm{ZnO}$ nanoflowers on PAA hydrogel.

Table 1. FT-IR functional groups of PAA and $\mathrm{ZnO} / \mathrm{PAA}$ hydrogels.

\begin{tabular}{|c|c|c|}
\hline \multirow{2}{*}{$\begin{array}{c}\text { Functional } \\
\text { Groups }\end{array}$} & \multicolumn{2}{|c|}{ Wave Number $\left(\mathrm{cm}^{-1}\right)$} \\
\cline { 2 - 3 } & $\begin{array}{c}\text { PAA } \\
\text { Hydrogel }\end{array}$ & $\begin{array}{c}\text { ZnO/PAA } \\
\text { Hydrogel }\end{array}$ \\
\hline Zn-O groups & - & $\begin{array}{c}3835, \\
2152,2000\end{array}$ \\
\hline $\begin{array}{c}\text { C-H } \\
\text { stretching }\end{array}$ & 2935 & 2942 \\
\hline $\begin{array}{c}\mathrm{C}=\mathrm{O} \\
\text { stretching }\end{array}$ & 1695 & 1695,1542 \\
\hline $\begin{array}{c}\mathrm{C}=\mathrm{C} \\
\text { stretching }\end{array}$ & 1452 & 1404 \\
\hline $\begin{array}{c}\mathrm{C}-\mathrm{O} \\
\text { stretching }\end{array}$ & 1238,1155 & 1162 \\
\hline
\end{tabular}

The morphological structures of hydrogels were imaged by FESEM. It was defined the distribution of $\mathrm{ZnO}$ nanoflowers on polymer surface clearly. Fig. 4 showed that homogenous $\mathrm{ZnO}$ distribution on PAA hydrogel surface at $3 \mathrm{kx}$ magnification. Also, morphological differences were seen before and after deposition of $\mathrm{ZnO}$ nanoflowers at $1 \mathrm{kx}$ magnification.
The observed size and shaped of $\mathrm{ZnO}$ nanoflowers were seen in Fig. 5. ZnO nanoflowers were obtained on PAA hydrogels by using CBD technique at minimum deposition time without any breaks and splits. $\mathrm{ZnO}$ nanoflowers distributed on hydrogel's surface smoothly.
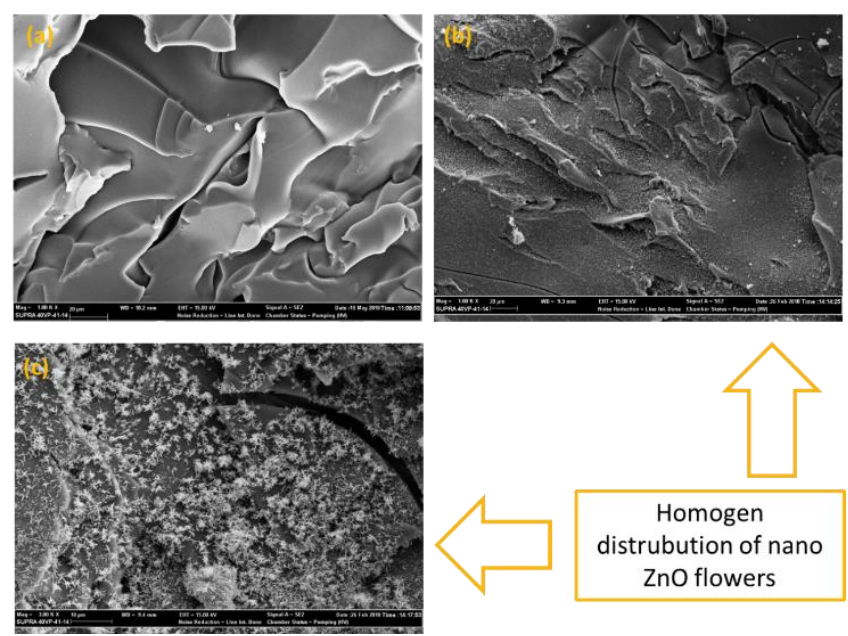

Figure 4. SEM images of (a) plain PAA hydrogel (1kx), (b) $\mathrm{ZnO}$ nanoflowers on PAA hydrogel (1kx) and (c) SEM image $\mathrm{ZnO}$ nano flowers on hydrogel (3kx).

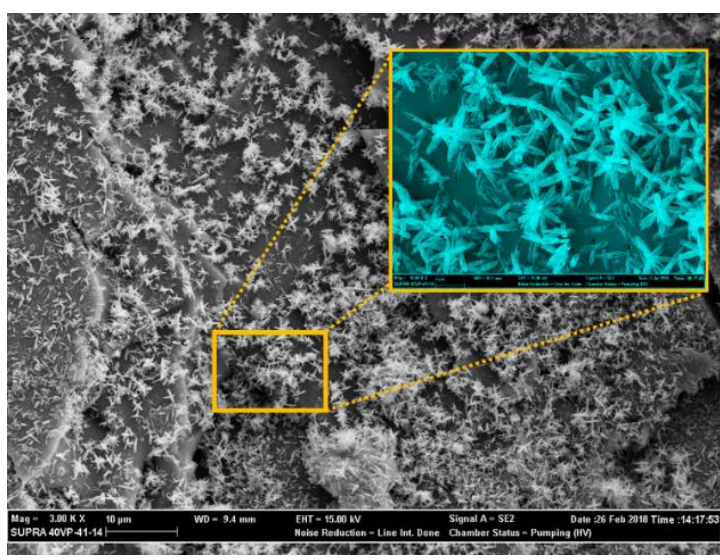

Figure 5. SEM image of $\mathrm{ZnO}$ nanoflowers on PAA hydrogel.

The elemental amount of $\mathrm{C}, \mathrm{O}$ and $\mathrm{Zn}$ were determined by EDX analysis. Amount of elements on PAA and ZnO/PAA hydrogels were given in Table 2. According to the Table 2, the $\mathrm{O}$ and $\mathrm{Zn}$ amounts were increased of after deposition.

Table 2. Amount of elements on PAA and $\mathrm{ZnO} / \mathrm{PAA}$ hydrogels

\begin{tabular}{|c|c|c|}
\hline Elements & $\begin{array}{c}\text { PAA } \\
\text { Hydrogel }\end{array}$ & $\begin{array}{c}\text { ZnO/PAA } \\
\text { Hydrogel }\end{array}$ \\
\hline $\mathrm{C}$ & $57.96 \%$ & $39.36 \%$ \\
\hline $\mathrm{O}$ & $42.04 \%$ & $45.45 \%$ \\
\hline $\mathrm{Zn}$ & - & $15.19 \%$ \\
\hline
\end{tabular}

Elemental mapping images of $\mathrm{ZnO}$ nanoflowers on hydrogel were given in Fig. 6. Zinc distribution was clearly seen in flower structures (in red color). 



Figure 6. Elemental mapping images of $\mathrm{ZnO}$ nanoflower on PAA hydrogel.

\section{CONCLUSIONS}

$\mathrm{ZnO} / \mathrm{PAA}$ biocompatible nanocomposite hydrogels were synthesized via a cost effective and simple method by using $\mathrm{CBD}$ technique. The effect of $\mathrm{ZnO}$ nanoflowers on structural and morphological properties of PAA hydrogels was investigated. Chemical bath solution at $\mathrm{pH} 10$ triggered the interactions between hydrogel and $\mathrm{ZnO}$ nanoparticles strongly in 30 minutes. The XRD patterns showed that $\mathrm{ZnO}$ nanoflowers were fully formed on PAA hydrogels. The FTIR spectrum proved that the characteristic absorption peaks of $\mathrm{Zn}-\mathrm{O}$ were at $2000 \mathrm{~cm}^{-1}, 2152 \mathrm{~cm}^{-1}$ and $3835 \mathrm{~cm}^{-1}$. FESEM images showed that the homogeneous morphology of $\mathrm{ZnO}$ nanoflowers. Nanoflowers were synthesized with an average size of $700 \mathrm{~nm}$. XRD, FT-IR spectroscopy and FESEM analysis evidenced the successful synthesize of $\mathrm{ZnO} / \mathrm{PAA}$ biocompatible nanocomposite hydrogels. In comparison with studies in literature, $\mathrm{ZnO}$ nanoparticle deposition were carried out in a very short time via CBD. The further studies can be done on antibacterial property of $\mathrm{ZnO} / \mathrm{PAA}$ hydrogels, due to its ability to kill bacteria rapidly.

\section{ACKNOWLEDGMENT}

The authors thank the Bilecik Seyh Edebali University Central Research Laboratory for the measurements and the support from Bilecik Seyh Edebali University Research Foundation (Project no: 2017-01.BSEU.28-01) is gratefully acknowledged.

[13] H. Wang, X. Gong, X. Guo, C. Liu, Y.Y. Fan, J. Zhang, B. Niu, and W. Li, "Characterization, release, and antioxidant activity of curcumin-loaded sodium alginate/ZnO hydrogel beads" Int J Biol Macromol. 121, $1118,2019$.

[14] J. Liu, Y. Wang, J. Ma, Y. Peng and A. Wang, “A review on bidirectional analogies between the photocatalysis and antibacterial properties of ZnO" Journal of Alloys and Compounds, 783, 898, 2018

[15] F.Ö. Gökmen, and N. Pekel Bayramgil, "Synthesis and characterization of $\mathrm{n}$-[3-(dimethyl-amino) propyl]

\section{REFERENCES}

[1] S.S. Kumar, P. Venkateswarlu, V.R. Rao, and G.N. Rao, "Synthesis, characterization and optical properties of zinc oxide nanoparticles" International Nano Letters, 3(30), 1, 2013.

[2] J.T. Illakkiya, "A Review On Optical Properties of Transition Metal Doped ZnO Nanostructures" International Journal of ChemTech Resea CODEN (USA): IJCRGG, 6(3), 2159, 2014.

[3] Z. Hu, G. Oskam, and P.C. Searson, "Influence of solvent on the growth of $\mathrm{ZnO}$ nanoparticles" J. Colloid and Interface Science, 263(2), 454, 2003.

[4] P. Sharma, K. Sreenivas, and K.V. Rao, "Analysis of ultraviolet photoconductivity in $\mathrm{ZnO}$ films prepared by unbalanced magnetron sputtering” J. Appl. Phys., 93, 3963, 2003.

[5] V.P. Kamat, R. Huehn, R.A. and Nicolasecu, "A sense and shoot approach for photocatalytic degradation of organic contaminants in water" J. Phys. Chem.B, 106(4), 788, 2002. [6] T. Satyanarayana, K.S. Rao, and G. Nagarjuna, "Synthesis, characterization, and spectroscopic properties of ZnO nanoparticles" ISRN Nanotechnology, 2012, 1, 2012.

[7] F. Ullah, M.B.H. Othman, F. Javed, Z. Ahmad, and H. Md-Akil, "Classification, processing and application of hydrogels: A review" Materials Science and Engineering C, 57, 4142015.

[8] I. Janik, , P. Ulanski, and J. M. Rosiak. "Pulse radiolysis of poly (vinyl methyl ether) in aqueous solution. Formation and structure of primary radicals."Nucl. Instrum. Methods Phys. Res., Sect. B, 151(1-4), 318, 1999.

[9] E. A. El-Hafian, E.S. Elgannoudi, A. Mainal, and A.H. Yahaya, "Characterization of chitosan in acetic acid: Rheological and thermal studies" Turk. J. Chem., 34, 47, 2010.

[10] A. Khan, M.B.H. Othman, K.A. Razak, and H.M. Akil, "Synthesis and physicochemical investigation of chitosanPMAA-based dual-responsive hydrogels" J. Polym. Res., 20, $1,2013$.

[11] F. Wahid, J.J. Yin, D.D. Xue, H. Xue, Y.S. Lu, C. Zhong, and L.Q. Chu, "Synthesis and characterization of antibacterial carboxymethyl Chitosan/ZnO nanocomposite hydrogels" Int J Biol Macromol. 88, 273, 2016.

[12] M. Yadollahi, I. Gholamali, H. Namazi, and M. Aghazadeh, "Synthesis and characterization of antibacterial carboxymethyl cellulose/ZnO nanocomposite hydrogels" Int J Biol Macromol. 74, 136, 2015.

methacrylamide / (nano- $\mathrm{SiO}_{2}$, amine-modified nano- $\mathrm{SiO}_{2}$ and expanded perlite) nanocomposite hydrogels" Eur. Chem. Bull., 6(11), 514, 2017.

[16] S. Temel, F.O. Gokmen, and E. Yaman, "Effects of Deposition Time on Structural and Morphological Properties of Synthesized $\mathrm{ZnO}$ Nanoflowers Without Using Complexing Agent” European Scientific Journal, 13(27), 28, 2017.

[17] S. Temel, F.Ö. Gökmen, and E. Yaman, "Short time synthesis of $\mathrm{ZnO}$ nanorods prepared by a hybrid deposition technique: effects of seed layer" International Journal of 
Current Advanced Research, 6(7), 4646, 2017.

[18] N.S. Rao and M.V.B. Rao, "Structural and optical investigation of $\mathrm{ZnO}$ nano powders synthesized from zinc chloride and zinc nitrate" American Journal of Materials Science, 5(3), 66, 2015. 